\title{
Grounding Characteristics of a Non-Pneumatic Mechanical Elastic Tire in a Rolling State with a Camber Angle
}

\author{
Xianbin Du1,* - Youqun Zhao ${ }^{2}$ - Qiang Wang1 - Hongxun Fu³ - Fen Lin ${ }^{2}$ \\ ${ }^{1}$ Shandong University of Science and Technology, College of Transportation, China \\ ${ }^{2}$ Nanjing University of Aeronautics and Astronautics, College of Energy and Power Engineering, China \\ ${ }^{3}$ Shandong University of Technology, School of Transportation and Vehicle Engineering, China
}

A non-pneumatic mechanical elastic tire (ME wheel) was introduced, and the grounding characteristics of the ME wheel under a rolling condition with a camber angle were investigated with the combination of finite element simulation and experimental research. According to the ME wheel structure and material characteristics, a numerical simulation model of the ME wheel was established using the finite element (FE) method. The stiffness tests were carried out to verify the accuracy of the simulation model of the ME wheel. To highlight the advantages of the ME wheel, an inflatable tire was selected as the reference tire, and the grounding characteristics of these two tires with different camber angles were compared and analysed in free rolling, braking, and driving conditions. Different slip ratio values for the ME wheel and inflatable tire were applied in driving conditions to analyse the influence of the slip ratio on the grounding characteristics. The obtained results indicated that both the ME wheel and inflatable tire will gradually suffer partial wear of the tread surface as the camber angle increases, but the pressure concentration of the inflatable tire is more serious. The research can provide a basis for structural optimization and comprehensive mechanical performance analysis of the ME wheel.

Keywords: wheel, grounding characteristics, finite element analysis, contact pressure, camber angle

Highlights

- An innovative safety tire with a catenary structure was introduced.

- An FE model of ME wheel which includes material nonlinear, large deformation and the anisotropy of rubber was established.

- The influence of the camber angle on the grounding characteristics of the ME wheel was analysed.

- The grounding characteristics of the ME wheel under different rolling states were compared and analysed with an inflatable tire.

- As the camber angle increases, both the ME wheel and inflatable tire will suffer partial wear of the tread, but it is more serious with the inflatable tire.

\section{INTRODUCTION}

The invention of the inflatable tire was a great advancement. It brings comfort and convenience to people, but it also brings new troubles such as nailing, leaking, and puncture [1] and [2]. According to the statistics from the transportation department of China, serious traffic accidents caused by tire leakage and bursting accounted for nearly $50 \%$ of the total accidents, especially on expressways [3].

To solve the problem of tire inflation-free and safety, many research and production departments have been devoted to the study of safety tire technology and achieved many positive results [4] to [6]. Michelin launched an inflation-free radial tire called "Tweel"; it is a single unit that replaces the current inflatable tire assembly [7]. Narasimhan et al. [8] analysed the influence of material factors on the vertical stiffness and vibration characteristics of the Tweel during the rolling state. Ma et al. [9] studied the interaction between the Tweel and soil using the finite element (FE) method, and the established model can be utilized to analyse traction characteristics on a particular terrain. Kim and Kim [10] analysed the load-carrying properties and ground pressure of a nonpneumatic tire with a hexagonal honeycomb structure. In addition, the application of leak-proof technology and run-flat tires has also greatly improved the safety of vehicles.

The mechanical elastic (ME) wheel investigated in the paper was a non-pneumatic safety tire with catenary structure, and it was developed to improve the mobility and safety of vehicles under harsh environment and driving conditions, such as rugged terrain and macadam pavement [11] and [12]. Since the ME wheel adopts a non-inflatable design, there is no danger of air leakage, puncture, etc. during the rolling process. Moreover, due to the use of a catenary structure, the ME wheel not only has the comfort and manoeuvrability of inflatable tires but also has the durability and damage resistance of airless tires.

As the basis of the vehicle system dynamics, many difficulties exist in the study of tire-pavement interaction. This is mainly due to the composite 
structure of a tire and its complex force and rolling conditions in the process of interaction with the pavement [13] and [14]. To deeply study the mechanical properties of tires, researchers have carried out a great deal of theoretical and experimental work and achieved fruitful results [15] to [17]. Song et al. [18] studied the temperature distribution of a tire under the rolling condition by the FE method. Nishiyama et al. [19] used a combination of finite element and discrete element to analyse the tire traction performance, and a new element conversion algorithm for interchanging between finite element and discrete element was developed to increase the computational efficiency. A tire-road coupled simulation system, which considers the viscoelastic characteristics of road and temperature fields, was developed by Han et al. [20] to analysed the track in various conditions. Tamada and Shiraishi [21] introduced a method of wear process simulation to predict the uneven wear of the tire, and the transformation of tire pattern shape and wear energy can be easily obtained with this method. Based on the mixed Lagrangian-Eulerian method, Wei et al. [22] and [23] proposed a new method to analyse the rolling noise of the tire. By comparing the simulation data with the test data, this new method has reliable prediction accuracy. Anderson and McPillan [24] studied the trade-off between tire wear and handling with a multi-objective optimization method and scaling factors derived from the Michelin TameTire model.

It can be seen that many achievements and experiences have been obtained in the study of tire mechanics. However, the research on the tire mechanics considering the effect of the camber angle is still relatively rare due to the complexity of the camber performance [25]. Kagami et al. [26] proposed an analytical method to analyse the contact deformation of a tire with the camber angle, and the predicted results were compared with the measured results. El-Gawwad et al. [27] presented a multispoke tire model to analyse the tire-terrain interaction and studied the effect of the camber angle on the tire performance.

Generally, the camber angle has a significant influence on the wheel steering and the rational selection of alignment parameters. The presence of the camber angle will result in a pair of opposite lateral forces on the tire, which will directly affect the lateral stability, dynamic and abnormal tread wear of the vehicle, especially in emergency situations such as sharp turn, obstacle avoidance, and overtaking. Therefore, it is necessary to study the grounding characteristics of ME wheel when considering the effect of the camber angle.

The primary objective of this research is to study the grounding characteristics of the ME wheel with camber angle in free rolling, braking and driving conditions. The cord-rubber composite was simulated by rebar model and the ME wheel finite element model was verified through the stiffness test. The pressure distribution of ME wheel and inflatable tire with different rolling conditions and camber angles were simulated, and the obtained simulation results were compared and discussed in detail. The research results can be a basis for the ME wheel structure optimization and compressive performance analysis.

\section{MAIN STRUCTURE COMPOSITION}

As a new type of safety tire, the ME wheel adopts an ingenious structural arrangement, which simplifies the traditional wheel and tire into an integrated structure. Fig. 1 shows the physical prototype of the ME wheel, and its main components include an external flexible tire body, a suspension hub, and multiple sets of hinges that are evenly distributed along the circumference of the ME wheel. The hinge mechanism is a three-bar structure. When the ME wheel is subjected to lateral force, a certain lateral deformation will occur due to the elasticity of the flexible tire body structure. The lateral stiffness of the ME wheel is larger than that of pneumatic tires under the same conditions so that the handling stability of the vehicle can be well ensured.

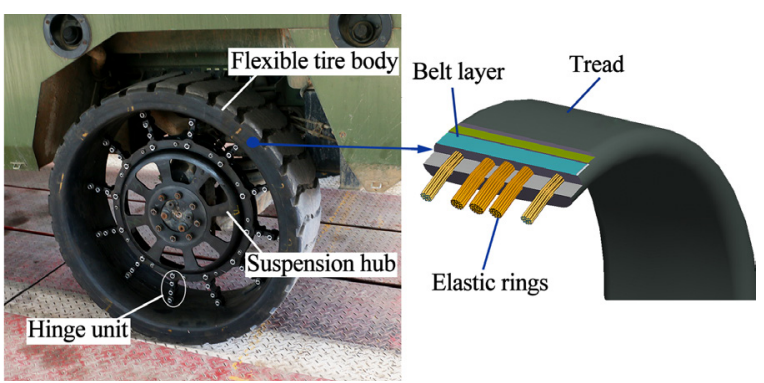

Fig. 1. Main structure composition of ME wheel

According to the physical dimension of the ME wheel, a $37 \times 12.5 \mathrm{R} 16.5$ type inflatable tire with a similar outer diameter and width was selected as a comparative reference tire for the grounding characteristics of the ME wheel, as shown in Fig. 2. The main physical dimensions of the ME wheel and the reference inflatable tire are shown in Table 1. 


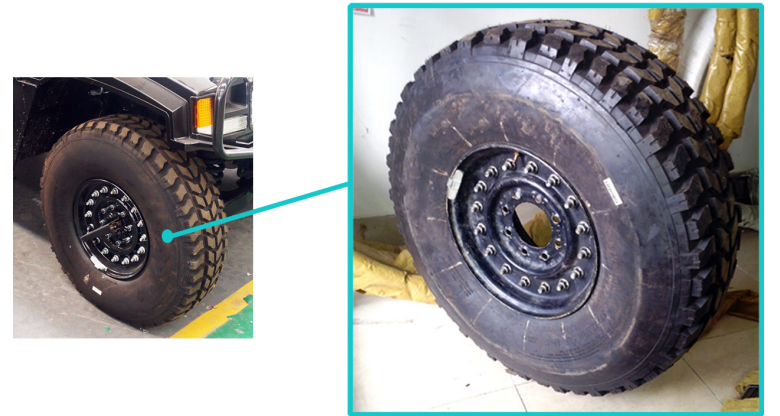

Fig. 2. Reference inflatable tire

Table 1. Comparison of key geometric parameters between the ME wheel and inflatable tire

\begin{tabular}{lcccc}
\hline Tire type & $\begin{array}{c}\text { Overall diameter } \\
{[\mathrm{mm}]}\end{array}$ & $\begin{array}{c}\text { Tread width } \\
{[\mathrm{mm}]}\end{array}$ & $\begin{array}{c}\text { Rim diameter } \\
{[\mathrm{mm}]}\end{array}$ & $\begin{array}{c}\text { Aspect } \\
\text { ratio }\end{array}$ \\
\hline ME wheel & 943.5 & 312.0 & - & - \\
\hline Inflatable tire & 939.8 & 317.5 & 419.1 & 0.82 \\
\hline
\end{tabular}

\section{NUMERICAL SIMULATION MODELLING}

\subsection{ME Wheel Model}

FE analysis discretizes the continuous geometric structure into finite elements and sets finite nodes in each element; thus, the continuum is discretized into a set of elements connected by nodes. The FE method has been an essential part of tire research, and various mechanical properties of the tire can be analysed according to different material properties, geometric contours, loads and boundary conditions [28] and [29].

The flexible tire body of a ME wheel contains multiple layers of cord-rubber composites with different mechanical properties, and the materials constituting ME wheel mainly include rubber, fibre cord, alloy steel and spring steel. Since rubber is a hyper-elastic material with a nearly incompressible volume, the Mooney-Rivlin constitutive model was utilized to describe the behaviour of it. The determination of the material parameters for the $\mathrm{ME}$ wheel was displayed in reference [30].

The three-dimensional (3D) FE model of the ME wheel, established by ABAQUS, was shown in Fig. 3. In the modelling process, the structure of the ME wheel was simplified properly on the premise of ensuring the reliability of the results, such as removing some edges and corners of the wheel and ignoring the influence of tread patterns. The rubber layer of the ME wheel was meshed with an 8-node linear brick, reduced integration unit C3D8R, and the elastic rings embedded in the flexible tire body were modelled using linear beam unit B31. The rebar model is that the reinforcement and the base are respectively represented by the rebar element and solid element, and it can express the base and the stiffener in different constitutive relations [31]. When modelling the cordrubber composites, the rebar model was utilized, and the cord-rubber composites were decomposed into the rubber base part and cord reinforcement part. Other components of the ME wheel, such as suspension hub and hinges, were also simulated with C3D8R [32].

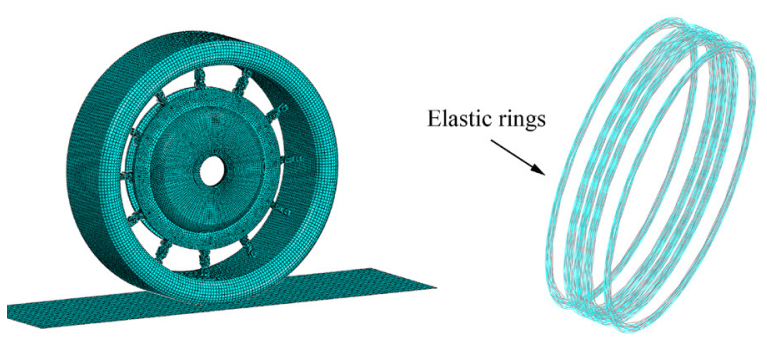

Fig. 3. FE model of ME wheel

The hinges and other parts of the wheel were connected by nodes, and a hinge connector was adapted to simulate the rotation of the mechanism. The contact definition between wheel components was defined as general contact, and the contact type between wheel and road surface was defined as surface-to-surface contact. The friction coefficient between the tread and road was assumed to be 0.6. The selection of mesh parameters needs to be of good accuracy and still have high computational efficiency. Under initial boundary condition, a fixed constraint was imposed on the road, and then steadystate transport analysis was used to perform numerical calculations.

\subsection{Inflatable Tire Model}

The structural characteristics of the inflatable tire are similar to those of the flexible tire body of the ME wheel. As the relative motion between the rim and the bead is small during the rolling process of the inflatable tire, the contact problem between the tire bead and the rim was simplified by limiting the degree of freedom (DOF) of the elements near the rim when the inflatable tire was modelled with the FE method.

As displayed in Fig. 4a, the two-dimensional (2D) axisymmetric FE model of the inflatable tire was established by ABAQUS, and then the 3D FE model of the tire was generated by rotating the $2 \mathrm{D}$ section model. The triangular elements and the quadrilateral elements of the rubber material were simulated by the linear axisymmetric hybrid element $\mathrm{CGAX} 3 \mathrm{H}$ and the bilinear axisymmetric hybrid element CGAX4H. The 
cord was modelled by linear axisymmetric element SFMGAX1. Additionally, to improve the calculation efficiency and obtain more accurate simulation results, mesh refinement was carried out near the contact patch when the 3D FE model of the inflatable tire was generated, as shown in Fig. 4b. The material parameters required for the modelling of tire referred to the data in [33], and the completed tire model consists of 62,328 elements and 69,521 nodes. a)

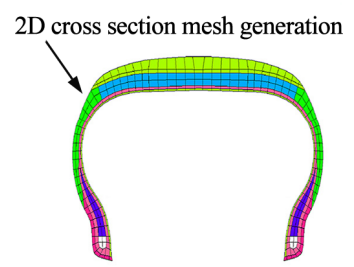

b)

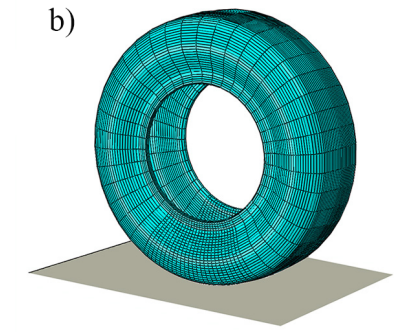

Fig. 4. a) 2D cross-section; b) 3D FEM model of inflatable tire

\section{FE MODEL VALIDATION}

\subsection{Stiffness Test}

It is necessary to verify the accuracy and reliability of the tire FE model before virtual simulation experiments are carried out. The vertical stiffness, longitudinal stiffness, and lateral stiffness of the ME wheel [33] were tested by a tire test rig, as shown in Fig. 5.

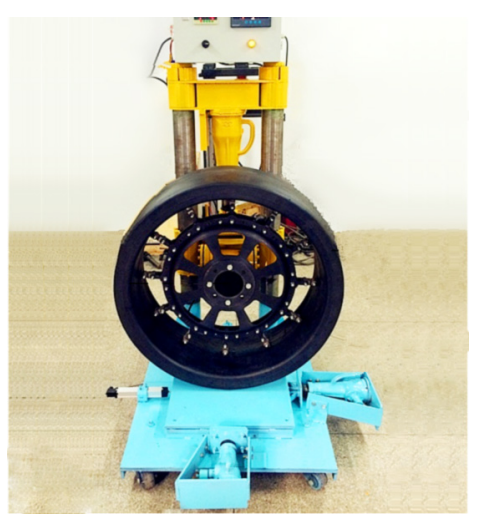

Fig. 5. Stiffness test of the ME wheel

The vertical stiffness of the tire has a significant influence on the bearing capacity, vibration and ride comfort of the vehicle. Fig. 6 shows the simulation and test data of wheel deflection under different vertical loads. It is easy to see that the deflection almost increases in line with the increase of the vertical load when the load is small, but as the vertical load increases, the increasing trend of wheel deflection decreases gradually. Moreover, the simulation data and test data are in good agreement.

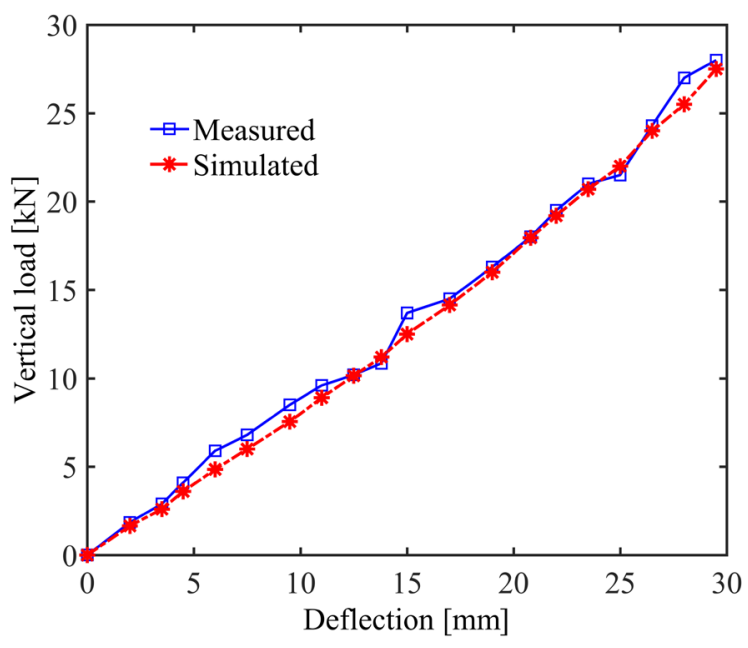

Fig. 6. The relationship between the vertical load and deflection

In Fig. 7, the simulation results of the longitudinal and lateral stiffness characteristics of the ME wheel are compared with the test results when the vertical load $F_{Z}$ is $9.5 \mathrm{kN}$ and $15 \mathrm{kN}$, respectively. It shows that the predicted variation characteristics of the longitudinal displacement and lateral displacement of the ME wheel are essentially consistent with the experimental data.
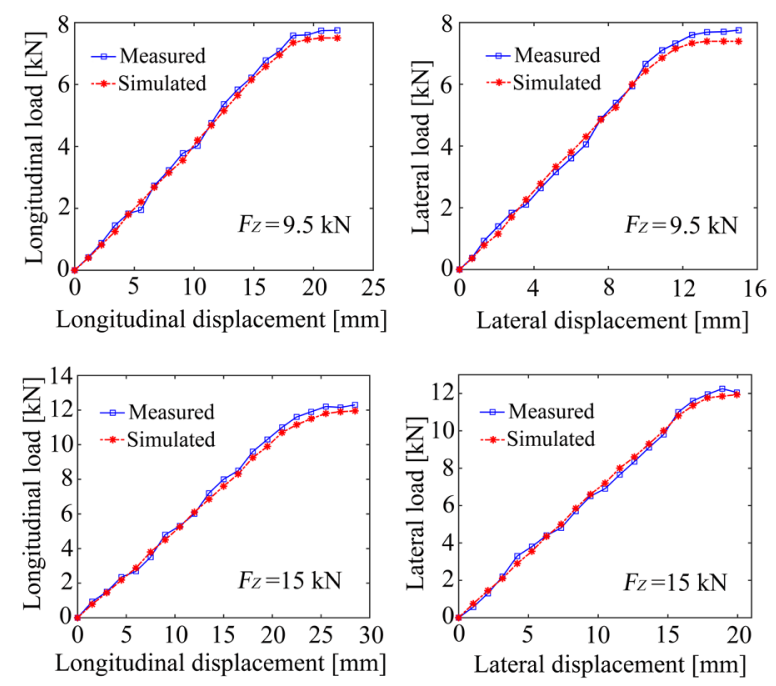

Fig. 7. Simulation and test data of the longitudinal and lateral stiffness characteristics under different loads

Table 2 shows the average relative error statistics for the vertical stiffness, longitudinal stiffness and lateral stiffness of the ME wheel. From the data in the 
table, it is observed that the average relative errors between the test and simulation values are about $5 \%$. Therefore, combining the above-mentioned comparative analysis, the following conclusions can be obtained: the numerical simulation model of the ME wheel has fine reliability and accuracy; therefore, it can be used for the subsequent virtual experiment simulation of the wheel's mechanical characteristics under different working conditions.

Table 2. Average relative error statistics of simulation results

\begin{tabular}{lcc}
\hline \multirow{2}{*}{ Stiffness type } & \multicolumn{2}{c}{ Average relative error [\%] } \\
\cline { 2 - 3 } & $F_{Z}=9.5 \mathrm{kN}$ & $F_{Z}=15.5 \mathrm{kN}$ \\
\hline Vertical stiffness & 5.12 & 5.12 \\
\hline Longitudinal stiffness & 4.02 & 4.41 \\
\hline Lateral stiffness & 5.28 & 5.02 \\
\hline
\end{tabular}

\subsection{Inflatable Profile and Load Characteristics Test}

To verify the accuracy of the FE model of the inflatable tire, the simulation results, including the inflated contour size of the inflatable tire and the relationship between the load and deflection, were compared with the experimental results.

The simulation values and measured values of section width and outer perimeter of the inflatable tire under two different inflation pressure conditions are displayed in Table 3, and the maximum relative error was $1.25 \%$.
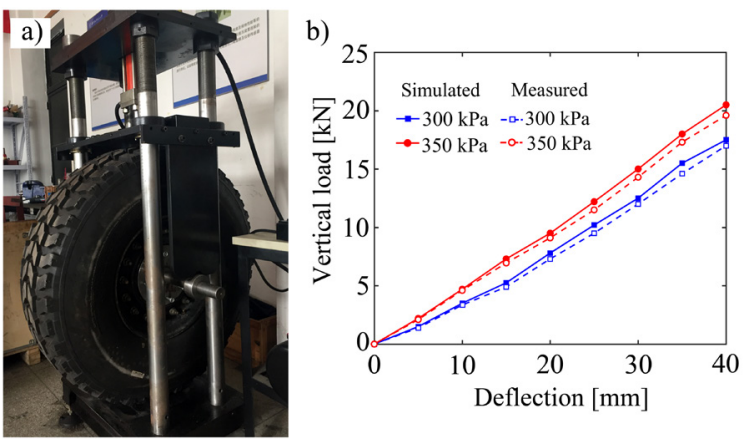

Fig. 8. a) Load characteristics test; b) comparison between test and simulation data

As displayed in Fig. 8, the load characteristics tests of the inflatable tire under two different inflation pressures $(300 \mathrm{kPa}$ and $350 \mathrm{kPa})$ were carried out on a vertical loading test rig. It can be seen from Fig. $8 \mathrm{~b}$ that the test curve of the inflatable tire has a high degree of coincidence with the simulation curve, and the average errors are $3.8 \%$ and $4.3 \%$, respectively. Consequently, the established FE model of the inflatable tire has high accuracy, and the result of the virtual simulation test is reliable.

\section{DETERMINATION OF ROLLING RADIUS}

When the tire is rolling at the same translational velocity, different angular velocities correspond to three different rolling states: free rolling, braking, and driving. It is necessary to specify the angular velocity of the tire and the translational velocity of the road surface separately when simulating the steady-state rolling of the tire. Since free rolling is a critical state between braking and driving, the rolling angular velocity and rolling radius of the tire under the freerolling condition should, therefore, be determined before the steady-state rolling simulation analysis of the tire was carried out. When the tire is in the freerolling state, the sideslip angle, the camber angle, and the longitudinal force are zero, and the actual radius is the free-rolling radius of the tire.

To determine the free-rolling angular velocity of the tire under a certain load and speed condition, the tire's translational velocity was first divided by an estimated rolling radius, and then an approximate range of the free-rolling angular velocity can be obtained. Under the condition that the tire's translational velocity was kept constant, the longitudinal forces corresponding to different angular velocities within the estimated range were calculated. When the longitudinal force was zero, the corresponding rolling angular velocity was the freerolling angular velocity of the tire.

Taking the inflatable tire studied in this paper as an example, the free radius is approximately 469.9 $\mathrm{mm}$, and the static radius is $450.08 \mathrm{~mm}$ with a tire pressure of $350 \mathrm{kPa}$ and a vertical load of $8000 \mathrm{~N}$. The free-rolling radius should be between the free radius and the static radius, assuming that it is $460 \mathrm{~mm}$, and then the corresponding rolling angular velocity is

Table 3. Inflated contour size of the inflatable tire

\begin{tabular}{|c|c|c|c|c|c|c|}
\hline \multirow{2}{*}{$\begin{array}{l}\text { Inflation pressure } \\
{[\mathrm{kPa}]}\end{array}$} & \multicolumn{2}{|c|}{ Section width [mm] } & \multirow{2}{*}{$\begin{array}{c}\text { Relative error } \\
{[\%]}\end{array}$} & \multicolumn{2}{|c|}{ Outer perimeter [mm] } & \multirow{2}{*}{$\begin{array}{c}\text { Relative errol } \\
{[\%]}\end{array}$} \\
\hline & Simulated & Measured & & Simulated & Measured & \\
\hline 300 & 315.22 & 319 & 1.18 & 2953.65 & 2991 & 1.25 \\
\hline 350 & 318.56 & 322 & 1.06 & 2986.28 & 3018 & 1.05 \\
\hline
\end{tabular}


$6.038 \mathrm{rad} / \mathrm{s}$ when the translational velocity is $10 \mathrm{~km} / \mathrm{h}$. Therefore, the angular velocity range can be set to $5.8 \mathrm{rad} / \mathrm{s}$ to $6.2 \mathrm{rad} / \mathrm{s}$, and then the relationship curve between angular velocity and longitudinal force in this interval can be obtained through simulation analysis, as shown in Fig. 9. It can be seen that the angular velocity is $5.97 \mathrm{rad} / \mathrm{s}$ when the longitudinal force is $0 \mathrm{kN}$, and the corresponding free-rolling radius is $465.28 \mathrm{~mm}$. The same method can be used to calculate the free-rolling angular velocity of the ME wheel with a vertical load of $8000 \mathrm{~N}$ and a translational velocity of $10 \mathrm{~km} / \mathrm{h}$. Finally, the calculated free-rolling angular velocity is $5.96 \mathrm{rad} / \mathrm{s}$, and the corresponding freerolling radius of the $\mathrm{ME}$ wheel is $466.32 \mathrm{~mm}$.

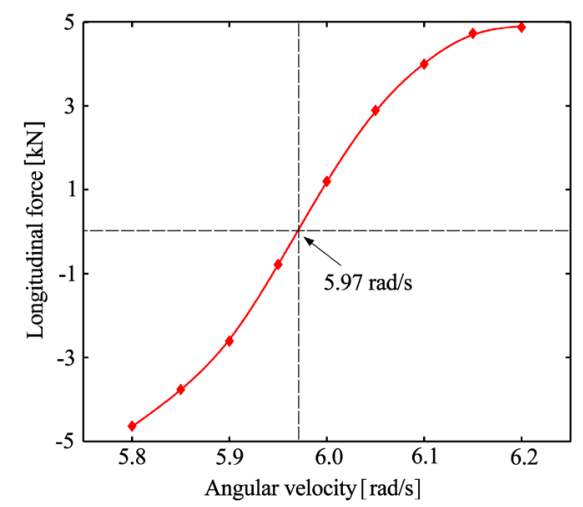

Fig. 9. Relationship between longitudinal force and angular velocity of inflatable tire

\section{RESULTS AND DISCUSSION}

In order to analyse the pressure distribution characteristics in the contact patch of the ME wheel and inflatable tire, as shown in Fig. 10, five sets of path nodes parallel to each other along the length of the ground contact imprint were established on the tread surface of ME wheel and inflatable tire. Each path consists of 17 nodes, of which the path 3 passes through the centre line of the tread surface, and the other four paths are symmetrically distributed on the upper and lower ends of the ground imprint.

\subsection{Free-Rolling Condition}

To investigate the influence of the camber angle on the ground pressure distribution under the freerolling condition, the ME wheel or inflatable tire was maintained in a free-rolling state, and the road was rotated along the wheel's motion direction by a certain angle, which was the camber angle for the simulation analysis. When the vertical load was $8 \mathrm{kN}$, and the translational velocity was $10 \mathrm{~km} / \mathrm{h}$, the grounding characteristics of the ME wheel and inflatable tire were analysed. Fig. 11 displays the comparison of the 3D contact pressure distribution curves of the ME wheel and inflatable tire (inflation pressure 350 $\mathrm{kPa}$ ) when the camber angle $\gamma$ was $2^{\circ}, 4^{\circ}, 6^{\circ}$, and $12^{\circ}$, respectively.

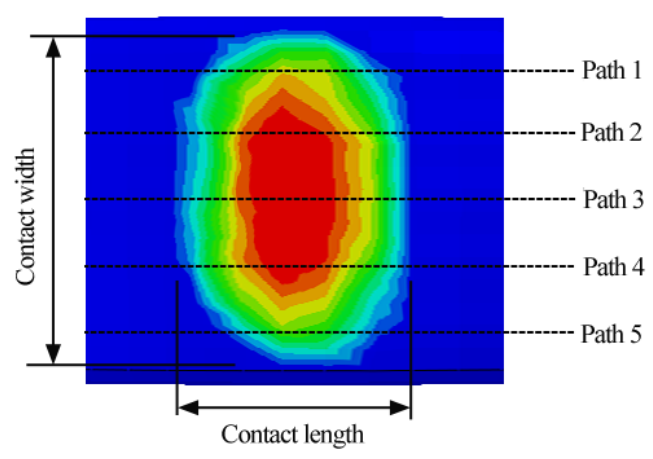

Fig. 10. The location sketch of the selected node sets along the length of the ground imprint

Comparing the variation of the contact pressure curves in Fig. 11, it can be seen clearly that the contact pressure is basically symmetrical with respect to the centreline along the width of the ground imprint. As the camber angle increases, the contact pressure of both the ME wheel and the inflatable tire will gradually concentrate on the side of the tread surface. In addition, the ground contact area becomes smaller, and the uniformity of the pressure distribution becomes worse with the increase of the camber angle. Both the ME wheel and the inflatable tire will suffer the partial wear of the tread surface.

Horizontal comparison of the ground pressure of the ME wheel and inflatable tire at the same camber angle was performed. As displayed in Fig. 11, when the camber angle is $2^{\circ}$, the maximum ground pressure of the ME wheel is distributed in the central area of the contact patch and the pressure decreases gradually from the centre to both sides, while the ground pressure of the inflatable tire at the centre of the contact patch is smaller than that of both sides, showing a similar saddle-shaped pressure distribution characteristic. When the camber angle is $4^{\circ}$, the maximum ground pressure of both $\mathrm{ME}$ wheel and inflatable tire moves to the roll side, but the moving speed of the maximum pressure of the inflatable tire is obviously higher than the maximum pressure of the ME wheel. At this point, the uniformity of the ground pressure of the ME wheel is slightly better than that of the inflatable tire. When the camber angle rises to $6^{\circ}$, the maximum ground pressure position of both tires is 

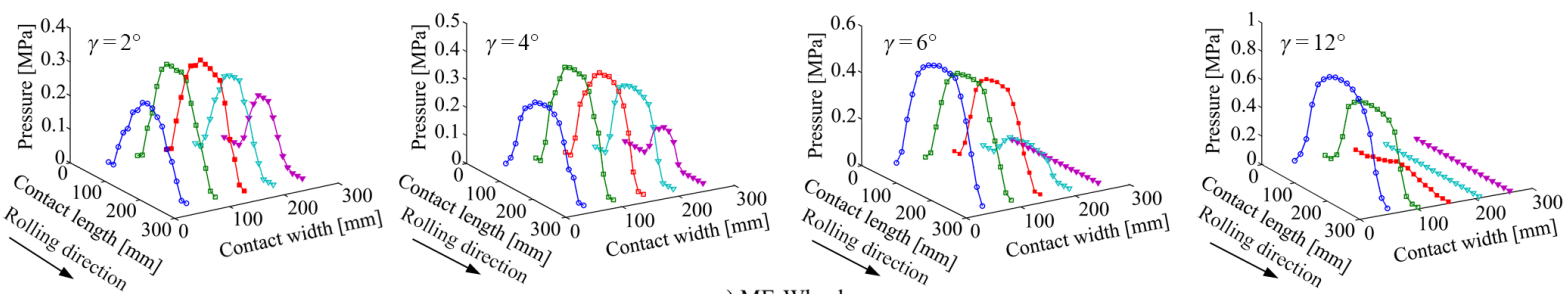

a) ME Wheel
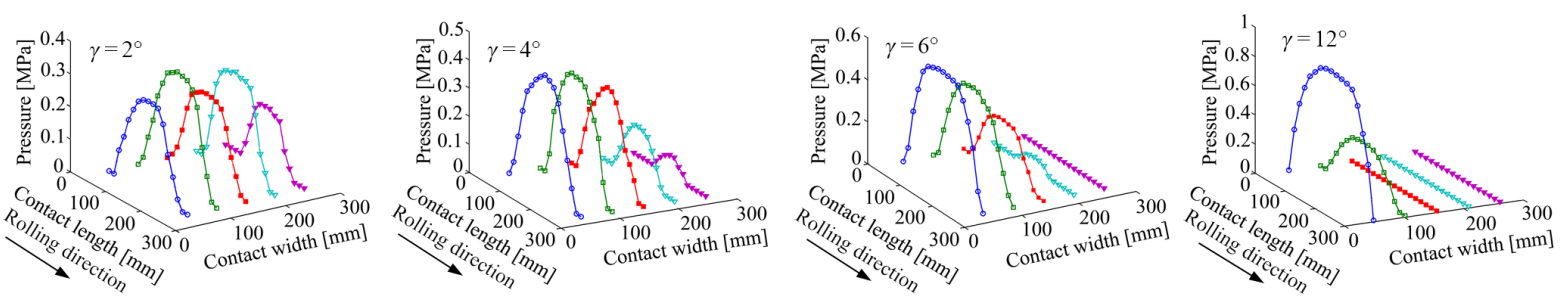

b) Inflatable tire

Fig. 11. Pressure distribution in free-rolling condition with different camber angles

located at the outermost side of the tire tilt direction. As the camber angle increases, the outermost ground pressure continues to increase, and the uniformity of the pressure distribution further deteriorates. When the camber angle reaches $12^{\circ}$, the ground pressure of the ME wheel and the inflatable tire is almost all concentrated on one side of the shoulder, but the pressure concentration of the inflatable tire is more serious at this time, and the partial wear of the tread will be aggravated.

Table 4 shows the comparison data of the predicted maximum contact pressure of the ME wheel and the inflatable tire under free-rolling conditions. It is observed that the maximum contact pressure of the
ME wheel is slightly less than that of the inflatable tire at the same camber angle. Moreover, the growth trend of the maximum contact pressure of both ME wheel and inflatable tire is gradually accelerating as the camber angle increases.

Table 4. Predicted maximum contact pressure of the ME wheel and inflatable tire in free free-rolling condition

\begin{tabular}{lcc}
\hline$\gamma\left[^{\circ}\right]$ & \multicolumn{2}{c}{ Maximum contact pressure [MPa] } \\
\cline { 2 - 3 } & ME wheel & Inflatable tire \\
\hline 2 & 0.362 & 0.383 \\
\hline 4 & 0.391 & 0.425 \\
\hline 6 & 0.464 & 0.503 \\
\hline 12 & 0.765 & 0.871 \\
\hline
\end{tabular}
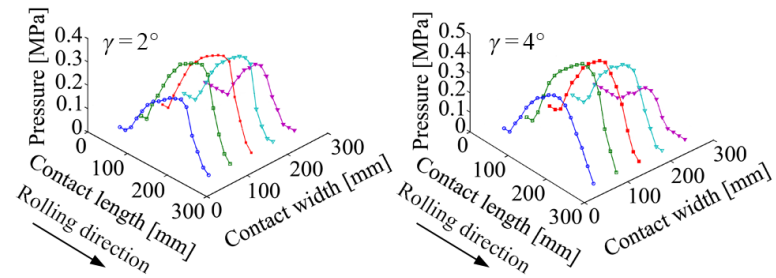
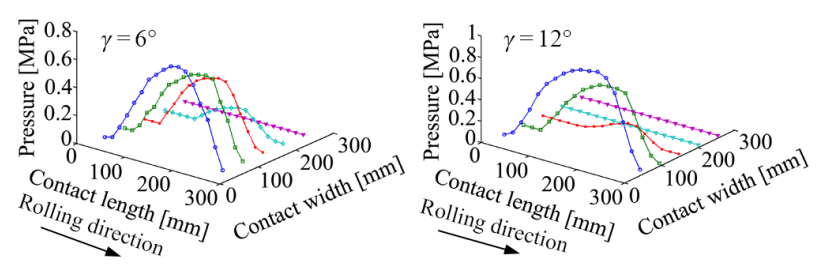

a) ME Wheel
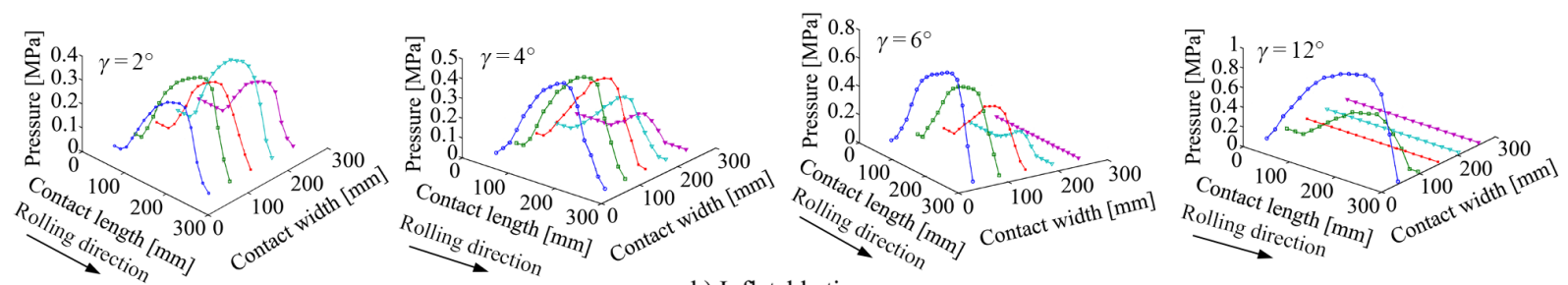

b) Inflatable tire

Fig. 12. Pressure distribution in braking condition with different camber angles 


\subsection{Braking Condition}

Under braking conditions, different rolling angular velocities will lead to different slip states. The slip ratio formula is defined as:

$$
s=\left(u_{x}-R_{e} w\right) / u_{x}
$$

where $s$ is the slip ratio of the tire, $u_{x}$ is translational velocity, $R_{e}$ is the rolling radius, and $w$ is the angular velocity. When the translational velocity of the $\mathrm{ME}$ wheel and inflatable tire was set to $10 \mathrm{~km} / \mathrm{h}$ and the rolling angular velocity was set to $5.48 \mathrm{rad} / \mathrm{s}$ and 5.50 $\mathrm{rad} / \mathrm{s}$ respectively, the braking slip ratio of both tires was $8 \%$.

Fig. 12 shows the ground pressure curves of these two tires with a slip ratio of $8 \%$ and a camber angle of $2^{\circ}, 4^{\circ}, 6^{\circ}$, and $12^{\circ}$, respectively. By comparing the distribution characteristics of the pressure curves, it is easily observed that the influence of the camber angle on the ground pressure of the two tires is similar to that of the free-rolling state under the braking condition, and the ground pressure is concentrated toward the shoulder portion of the tire roll side, resulting in uneven wear of the tread. However, unlike the freerolling state, the ground pressure in the braking state is no longer symmetrical about the central line along the width of the ground imprint, and the high ground pressure zone is gradually shifted to the front part of the tire movement direction.
Table 5 shows the maximum contact pressure of the ME wheel and inflatable tire in braking conditions. It can be seen that the variation trend of the maximum pressure value is similar to that of the free-rolling condition, but the maximum pressure under the braking condition is larger than that under the freerolling condition when the camber angle is the same.

Table 5. Predicted maximum contact pressure of the ME wheel and inflatable tire in braking condition

\begin{tabular}{lcc}
\hline \multirow{2}{*}[^{\circ}]{} & \multicolumn{2}{c}{ Maximum contact pressure [MPa] } \\
\cline { 2 - 3 } & ME wheel & Inflatable tire \\
\hline 2 & 0.360 & 0.379 \\
\hline 4 & 0.449 & 0.465 \\
\hline 6 & 0.651 & 0.683 \\
\hline 12 & 0.835 & 0.972 \\
\hline
\end{tabular}

\subsection{Driving Condition}

When the rolling angular velocity of the tire is greater than the free-rolling angular velocity, the longitudinal force generated between the tire and the road surface will push the tire forward, at which time the tire is in the driving condition. To analyse the influence of the slip ratio on the ground pressure, the pressure distribution characteristics of the ME wheel and the inflatable tire at different slip ratios were analysed.

Fig. 13 shows the 3D ground pressure characteristic curves of the ME wheel and inflatable

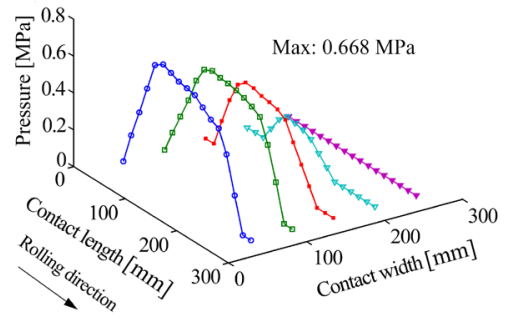

a) ME Wheel $\gamma=6^{\circ} \mathrm{s}=-8 \%$

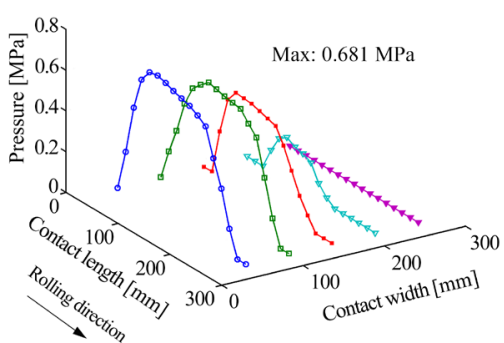

c) ME Wheel $\gamma=6^{\circ} \mathrm{s}=-11 \%$

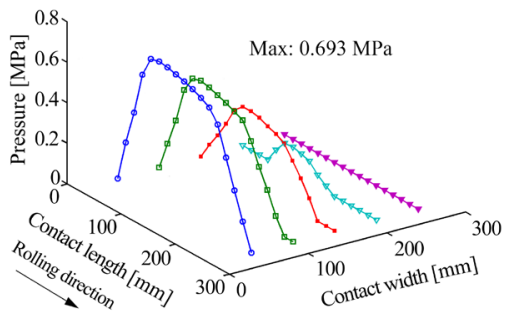

b) Inflatable tire $\gamma=6^{\circ} \mathrm{s}=-8 \%$

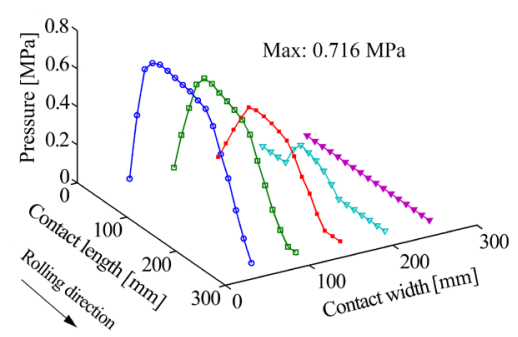

d) Inflatable tire $\gamma=6^{\circ} s=-11 \%$

Fig. 13. Pressure distribution in driving condition 
tire at the slip ratio of $-8 \%$ and $-11 \%$ when the camber angle is $6^{\circ}$. It can be seen that the pressure distribution of the ME wheel and the inflatable tire in the driving condition is also no longer symmetrical about the centreline along the width of the ground mark; however, the moving direction of the highpressure zone is opposite to that in the braking condition, and is offset to the back end of the contact area. As seen clearly, for the slip ratio of $-8 \%$, the maximum ground pressure of the $\mathrm{ME}$ wheel and the inflatable tire is $0.668 \mathrm{MPa}$ and $0.693 \mathrm{MPa}$, respectively, and when the slip ratio increases to $-11 \%$, the maximum pressure values of these two tires are $0.681 \mathrm{MPa}$ and $0.716 \mathrm{MPa}$, respectively. Consequently, it can be concluded that the maximum pressure value of the contact patch increases as the slip ratio increases when the camber angle remains constant.

\section{CONCLUSIONS}

The grounding characteristics of the ME wheel with a camber angle in free-rolling, braking and driving conditions were studied by finite element analysis and bench tests in this paper, and the simulation results of grounding characteristics for the ME wheel and inflatable tire under the same rolling conditions were compared and analysed. The main conclusions were summarized as follows:

1. The ground pressure of the ME wheel is substantially symmetrical about the centre line along the width direction of the grounding mark in free-rolling condition. Meanwhile, as the camber angle increases, the ground pressure of the ME wheel and inflatable tire will be concentrated toward the roll side, and the uniformity of the pressure distribution gradually deteriorates; therefore, both the ME wheel and inflatable tire will suffer the partial wear of the tread.

2. The moving speed of maximum ground pressure of the ME wheel is significantly less than that of the inflatable tire in free-rolling condition, which results in the pressure concentration of the inflatable tire being more serious than the $\mathrm{ME}$ wheel when the camber angle is large, and the resulting tread wear is also aggravated.

3. Under braking condition, the effect of the camber angle on the pressure distribution of the $\mathrm{ME}$ wheel is similar to that in free-rolling condition, however, the ground pressure of the ME wheel in braking state is no longer symmetrical with respect to the centre line along the width of the grounding imprint, and the high-pressure zone gradually shifts to the front of the moving direction.

4. The moving direction of the high-pressure zone of the ME wheel in the driving condition is opposite to that in the braking condition, offsetting the rear end of the contact patch. In addition, the maximum pressure of the contact patch increases with the increase of slip ratio when the camber angle remains unchanged.

\section{ACKNOWLEDGEMENTS}

This work was supported by the Scientific Exploration Fund of the General Armament Department of China (No. NHA13002), the Funding of the Jiangsu Innovation Program for Graduate Education (No. KYLX15_0254) and the Scientific Research Foundation of Shandong University of Science and Technology for Recruited Talents.

\section{REFERENCES}

[1] Baranowski, P., Malachowski, J., Mazurkiewicz, L. (2016). Numerical and experimental testing of vehicle tyre under impulse loading conditions. International Journal of Mechanical Sciences, vol. 106, p. 346-356, D0l:10.1016/j. ijmecsci.2015.12.028.

[2] Cho, J.R., Lee, J.H., Jeong, K.M., Kim, K.W. (2012). Optimum design of run-flat tire insert rubber by genetic algorithm. Finite Element in Analysis and Design, vol. 52, p. 60-70, DOl:10.1016/j.finel.2011.12.006.

[3] Zhao, Y.Q., Zang, L.G., Chen, Y.Q., Li, B., Wang, J. (2015). Non-pneumatic mechanical elastic wheel natural dynamic characteristics and influencing factors. Journal of Central South University, vol. 22, no. 5, p. 1707-1715, D0l:10.1007/ s11771-015-2689-1.

[4] Jin, X.C., Hou, C., Fan, X.L., Sun, Y.L., Lv, J., Lu, C.S. (2018). Investigation on the static and dynamic behaviors of non-pneumatic tires with honeycomb spokes. Composite Structures, vol. 187, p. 27-35, Dol:10.1016/j. compstruct.2017.12.044.

[5] Kucewicz, M., Baranowski, P., Malachowski, J. (2016). Airless tire conceptions modeling and simulations. Proceedings of the 13th International Scientific Conference: Computer Aided Engineering, p. 293-301, D0l:10.1007/978-3-319-50938.

[6] Ju, J., Veeramurthy, M., Summers, J.D., Thompso, L. (2013). Rolling resistance of a non-pneumatic tire having a porous elastomer composite shear band. Tire Science and Technology, vol. 41, no. 3, p. 154-173, D0l:10.2346/ tire.13.410303.

[7] Jang, I.G., Sung, Y.H., Yoo, E.J., Kwak, B.M. (2012). Pattern design of a non-pneumatic tire for stiffness using topology optimization. Engineering Optimization, vol. 44, no. 2, p. 119131, DOI:10.1080/0305215x.2011.569546.

[8] Narasimhan, A., Ziegert, J., Thompson, L. (2011). Effects of material properties on static load-deflection and vibration of 
a non-pneumatic tire during high-speed rolling. SAE Technical Paper, no. 2011-01-0101, D0l:10.4271/2011-01-0101.

[9] Ma, J.F., Kolla, A., Summers, J.D., Joseph, P.F., Blouin, V.Y., Biggers, S. (2009). Numerical simulation of new generation non-pneumatic tire (TWEELTM) and sand. Proceedings of the ASME International Design Engineering Technical Conferences and Computers and Information in Engineering Conference, p. 123-130, D0l:10.1115/detc2009-87263.

[10] Kim, K., Kim, D.M.(2011). Contact pressure of non-pneumatic tires with hexagonal lattice spokes. SAE Technical Paper, no. 2011-01-0099, D0I:10.4271/2011-01-0099.

[11] Du, X.B., Zhao, Y.Q., Wang, Q., Fu, H.X. (2017). Numerical analysis of the dynamic interaction between a non-pneumatic mechanical elastic wheel and soil containing an obstacle. Proceedings of the Institution of Mechanical Engineers, Part D: Journal of Automobile Engineering, vol. 231, no. 6, p. 731742, Dol:10.1177/0954407016660946.

[12] Xiao, Z., Zhao, Y.Q., Lin, F., Zhu, M.M., Deng, Y.J. (2018). Studying the fatigue life of a non-pneumatic wheel by using finite-life design for life prediction. Strojniški vestnik Journal of Mechanical Engineering, vol. 64, no. 1, p. 56-67, D0l:10.554 5/sv-jme.2017.4695.

[13] Nakajima, Y. (2007). Application of optimisation technique to tire design. International Journal of Vehicle Design, vol. 43, no. 1-4, p. 49-65, D0I:10.1504/ijvd.2007.012295.

[14] Veeramurthy, M., Ju, J., Thompson, L., Summers, J.D. (2014). Optimisation of geometry and material properties of a nonpneumatic tyre for reducing rolling resistance. International Journal of Vehicle Design, vol. 66, no. 2, p. 193-216, DOI:10.1504/ijvd.2014.064567.

[15] Lee, J., Wang, S., Pluymers, B., Kindt, P. (2015). A modified complex modal testing technique for a rotating tire with a flexible ring model. Mechanical Systems and Signal Processing, vol. 60-61, p. 604-618, D0l:10.1016/j. ymssp.2014.12.002.

[16] Hoever, C., Kropp, W. (2015). A model for investigating the influence of road surface texture and tyre tread pattern on rolling resistance. Journal of Sound and Vibration, vol. 351, p. 161-176, D0I:10.1016/j.jsv.2015.04.009.

[17] Baranowski, P., Malachowski, J. (2015). Numerical study of selected military vehicle chassis subjected to blast loading in terms of tire strength improving. Bulletin of Polish Academy of Sciences-Technical Sciences, vol. 63, no. 4, p. 867-878, DOl:10.1515/bpasts-2015-0099.

[18] Song, H.S., Jung, S.P., Park, T.W. (2018). Simulation of temperature rise within a rolling tire by using FE analysis. Journal of Mechnical Science and Technology, vol. 32, no. 7, p. 3419-3425, DOl:10.1007/s12206-018-0645-3.

[19] Nishiyama, K., Nakashima, H., Yoshida, T., Shimizu, H., Miyasaka, J., Ohdoi, K. (2018). FE-DEM with interchangeable modeling for off-road tire traction analysis. Journal of Terramechanics, vol. 78, p. 15-25, D0l:10.1016/j. jterra.2018.03.005.

[20] Han, D., Zhu, G.D., Hu, H.M., Li, L.L. (2018). Dynamic simulation analysis of the tire-pavement system considering temperature fields. Construction and Building Materials, vol. 171, p. 261-272, D0I:10.1016/j.conbuildmat.2018.03.071.

[21] Tamada, R., Shiraishi, M. (2017). Prediction of uneven tire wear using wear process simulation. Tire Science and Technology, vol. 45, no. 2, p. 87-100, Dol:10.2346/tire.17.450201.

[22] Wei, Y.T., Feng, X.J., Zhou, F.Q., Xiang, D.B. (2016). Simulation of rolling noise based on the mixed Lagrangian-Eulerian method. Tire Science and Technology, vol. 44, no. 1, p. 36-50, DOI:10.2346/tire.16.440103.

[23] Wei, Y.T., Oertel, C., Shen, X.L. (2012). Tyre rolling kinematics and prediction of tyre forces and moments: Part II - simulation and experiment. Vehicle System Dynamics, vol. 50, no. 11, p. 1689-1706, Dol:10.1080/00423114.2012.694453.

[24] Anderson, J.R., McPillan, E. (2016). Simulation of the wear and handling performance trade-off by using multi-objective optimization and TameTire. Tire Science and Technology, vol. 44, no. 4, p. 280-290, Dol:10.2346/tire.16.440404.

[25] Wozniak, R., Taryma, S., Mioduszewski, P. (2015). Tire camber angle influence on tire-pavement noise. Noise Control Engineering Journal, vol. 63, no. 3, p. 216-224, DOl:10.3397/1/376320.

[26] Kagami, S., Akasaka, T., Shiobara, H., Hasegawa, A. (1995). Analysis of the contact deformation of a radial tire with camber angle. Tire Science and Technology, vol. 23, no. 1, p. 26-51, Dol:10.234 6/1.2137494.

[27] El-Gawwad, K.A.A., Crolla, D.A., Soliman, A.M.A., El-Sayed, F.M. (1999). Off-road tyre modelling II: effect of camber on tyre performance. Journal of Terramechanics, vol. 36, no. 1, p. 2538, DOI:10.1016/s0022-4898(98)00032-9.

[28] Baranowski, P., Malachowski, J., Janiszewski, J., Wekezer, J. (2016). Detailed tyre FE modeling with multistage validation for dynamic analysis. Materials and Design, vol. 96, p. 68-79, DOl:10.1016/j.matdes.2016.02029.

[29] Guo, H., Bastien, C., Blundell, M., Wood, G. (2014). Development of a detailed aircraft tyre finite element model for safety assessment. Materials and Design, vol. 53, p. 902909, D0I:10.1016/j.matdes.2013.05.046.

[30] Du, X.B., Zhao, Y.Q., Lin, F., Xiao, Z. (2017). Parameters determination of Mooney-Rivlin model for rubber material of mechanical elastic wheel. Applied Mechanics and Materials, vol. 872 , p. 198-203, D0l:10.4028/www.scientific.net/ amm.872.198.

[31] Wang, H., Al-Qadi, I.L., Stanciulescu, I. (2014). Effect of surface friction on tire-pavement contact stresses during vehicle maneuvering. Journal of Engineering Mechanics, vol. 140, no. 10, p. 04014001, DOI:10.1061/(ASCE)EM.19437889.0000691.

[32] Zhao, Y.Q., Du, X.B., Lin, F., Wang, Q., Fu, H.X. (2018). Static stiffness characteristics of a new non-pneumatic tire with different hinge structure and distribution. Journal of Mechanical Science and Technology, vol. 32, no. 7, p. 30573064, DOI:10.1007/s12206-018-0608-8.

[33] Guan, Y.J., Zhao, G.Q., Cheng, G. (2006). Influence of belt cord angle on radial tire under different rolling states. Journal of Reinforced Plastics and Composites, vol. 25, no. 10, p. 10591077, DOI:10.1177/0731684406065000. 